\title{
Especialização e localização do valor bruto da produção dos produtos madeireiros nativos nas microrregiões da Paraíba (1994 - 2017)
}

\author{
Specialization and location of the gross value production of native wood \\ products in Paraíba's microrregions (1994 - 2017)
}

\author{
Luiz Moreira Coelho Junior ${ }^{\mathrm{I}}$, Edvaldo Pereira Santos Júnior ${ }^{\mathrm{II}}$, \\ Luís Antônio Coimbra Borges ${ }^{\mathrm{III}}$, Márcio Lopes da Silva ${ }^{\mathrm{IV}}$
}

\begin{abstract}
Resumo
Este artigo analisou o padrão de especialização e localização do Valor Bruto da Produção (VBP) dos produtos madeireiros nativos nas microrregiões da Paraíba de 1994 a 2017. A coleta de dados realizou-se a partir das informações disponíveis da Produção da Extração Vegetal e da Silvicultura (PEVS) do Instituto Brasileiro de Geografia e Estatística (IBGE). Os indicadores empregados foram: o quociente locacional $(Q L)$, o coeficiente locacional $(C L)$, o coeficiente de redistribuição $(C R E D)$, o coeficiente de associação geográfica $(C a g)$, o coeficiente de especialização $(C E)$ e o coeficiente de reestruturação $(C r)$. Os resultados evidenciaram que a lenha foi o principal produto madeireiro extraído nas microrregiões da Paraíba; apenas a microrregião do Serra de Teixeira apresentou relevância na extração de madeira em tora; a lenha foi o produto madeireiro que apresentou maior redistribuição; nos anos finais da análise as microrregiões do Litoral Norte e do Cariri Ocidental foram as mais especializadas, com ênfase na extração de lenha e as microrregiões do Litoral Norte, Cariri Ocidental, João Pessoa e Litoral Sul foram as que apresentaram maior mudança no padrão de extração dos produtos madeireiros com relação a 1994. A partir deste estudo é possível a orientação de políticas públicas que promovam o extrativismo vegetal de forma renovável para o suprimento da demanda energética e que possibilite o desenvolvimento de regiões.
\end{abstract}

Palavras-chave: Economia regional; Biomassa florestal; Extrativismo vegetal

\begin{abstract}
This article analyzed the pattern of the Gross Value Production (VBP) specialization and location of native wood products in Paraíba's microregions, from 1994 to 2017. The data collection was carried out from the available information of the Production of Plant Extraction and Silviculture (PEVS) of the Brazilian Institute of Geography and Statistics (IBGE). The indicators used were the locational quotient (QL), the locational coefficient (CL), the redistribution coefficient (CRED), the geographic association coefficient $(\mathrm{Cag})$, the specialization coefficient $(\mathrm{CE})$ and the restructuring coefficient $(\mathrm{Cr})$. The results showed that firewood was the main wood product extracted in Paraíba's microregions; only the microregion of Serra de Teixeira presented relevance in the extraction of wood in log; wood was the logging product that presented the greatest redistribution; in the final years of the analysis, the micro-regions of Litoal Norteand Cariri Ocidental were the most specialized, with emphasis on the extraction of firewood and the microregions of the Litoral Norte, Cariri Ocidental, João Pessoa and Litoral Sul were the ones that presented the greatest change in the extraction pattern of the products in relation to 1994. From this study, it is possible to guide public policies that promote renewable plant extraction to supply the energy demand and enable the development of regions.
\end{abstract}

Keywords: Regional economics; Forest biomass; Plant extractivism

Economista, Dr., Professor do Departamento de Engenharia de Energias Renováveis, Universidade Federal da Paraíba, Caixa Postal 5115, CEP 58.051-900, João Pessoa (PB), Brasil. luiz@cear.ufpb.br (ORCID: 0000-0001-5528-7799)

II Engenheiro de Energias Renováveis, Mestrando pelo Programa de Pós-Graduação em Energias Renováveis, Universidade Federal da Paraíba, Caixa Postal 5115, CEP 58.051-900, João Pessoa (PB), Brasil. edvaldo.junior@cear.ufpb.br (ORCID: 0000-0003-1316-2247)

III Engenheiro Florestal, Dr., Professor do Departamento de Ciências Florestais, Universidade Federal de Lavras, Caixa Postal 3037, CEP 37200-000, Lavras (MG), Brasil. luis.borges@dcf.ufla.br (ORCID: 0000-0003-0344-5008)

Iv Engenheiro Florestal, Dr., Professor do Departamento de Engenhraria Florestal, Universidade Federal de Viçosa, CEP 36570-900, Viçosa (MG), Brasil.marlosil@ufv.br (ORCID: 0000-0002-6742-4479) 


\section{Introdução}

Os produtos florestais, sejam obtidos da silvicultura ou da extração vegetal, podem ser classificados em madeiros ou não madeiros. Os madeireiros são todo insumo lenhoso de origem vegetal que pode ser utilizado como matéria prima industrial, para aquecimento, cocção de alimento, construção civil e para geração de energia; sendo dividido em madeira industrial, lenha e carvão vegetal e madeiras processadas. Por sua vez, os produtos não madeireiros são todo material não lenhoso de origem vegetal como as resinas, óleos e sementes utilizados na alimentação, cosméticos, artesanais e medicinais (BRASIL, 2018a).

Segundo o Instituto Brasileiro de Geografia e Estatística (IBGE, 2018), no Brasil os produtos madeireiros são classificados como lenha, carvão vegetal e madeira em tora. Em 2017, o valor bruto de produção (VBP) dos produtos madeireiros da extração vegetal, no Brasil, foi R\$ 2,78 bilhões, sendo $\mathrm{R} \$ 1,92$ bilhões da madeira em tora, $\mathrm{R} \$ 54,09$ milhões da lenha e $\mathrm{R} \$ 31,72$ milhões de carvão vegetal. Para o mesmo ano a produção oriunda da silvicultura foi de $\mathrm{R} \$ 14,44$ bilhões, sendo $\mathrm{R} \$ 9,59$ bilhões obtidos da madeira em tora, $\mathrm{R} \$ 2,57$ bilhões do carvão vegetal e $\mathrm{R} \$$ 2,28 bilhões da lenha. A região Norte apresentou a maior participação para produção madeireira a partir do extrativismo vegetal, em 2017, com $\mathrm{R} \$ 1,35$ bilhões; sendo a madeira em tora o recurso mais importante com participação de $88,95 \%$. O Centro-Oeste somou $\mathrm{R} \$ 719,63$ milhões, em 2017 , dos quais $\mathrm{R} \$ 543,91$ milhões foram da madeira em tora. O Nordeste, com $\mathrm{R} \$ 535,33$ milhões, caracterizou-se como a região de maior extração do país para a lenha ( $\mathrm{R} \$ 245,45$ milhões) e carvão vegetal (R\$200,67 milhões). Em seguida, as regiões Sul e Sudeste geraram 144,77 milhões e R\$ 30,64 milhões, respectivamente, sendo a lenha o principal recurso (IBGE, 2018).

O Nordeste brasileiro tem cerca $70 \%$ da cobertura vegetal sob influência do bioma da caatinga que é caracterizado por uma vegetação lenhosa e espinhosa. Grande parte da população que vive nesse bioma utiliza os recursos oferecidos nele para sua subsistência, a partir da produção de medicamentos, materiais para construção civil e principalmente do comércio da lenha e carvão vegetal (LUCENA et al., 2012). Em 2017, os estados que mais contribuíram com o VBP dos produtos madeireiros na região foram: Maranhão (R \$ 169,65 milhões), Bahia (R\$122,30 milhões) e Piauí (R\$ 78,53 milhões) (IBGE, 2018).

Para Travassos e Sousa (2014), o uso da madeira nativa na Paraíba se assemelha ao dos demais estados nordestinos, onde a lenha e o carvão vegetal são importantes para o uso residencial, comércio local e regional e como fonte energética industrial, com destaque para o consumo nas indústrias de cerâmica vermelha e polos gesseiros do estado (COELHO JUNIOR; BURGOS; SANTOS JUNIOR, 2018; MARTINS et al., 2018; REINALDO FILHO; BEZERRA, 2010). Em 2017, a Paraíba foi o sétimo estado que mais contribuiu para o VBP dos produtos madeireiros no Nordeste, com $\mathrm{R} \$ 12,92$ milhões, dos quais $94,08 \%$ foram da lenha e $5,92 \%$ do carvão vegetal (IBGE, 2018).

Os estudos de economia regional auxiliam a caracterização de estruturas produtivas e de especialização em uma determinada área, favorecendo o desenvolvimento de estratégias para otimização econômica (MATTEI; MATTEI, 2018). Para Haddad (1989), os elementos analíticos das avaliações estruturais são as medidas de especialização e/ou localização, para identificar e compreender os padrões de dispersão para um determinado período de tempo. Para o uso desses indicadores destacaram-se os trabalhos de: Carvalho et al. (2018), Cromley e Hanink (2012), Goschin et al. (2015), Mazur, Romero e Ecker (2013), Silva e Rodrigues (2018) e Sousa et al. (2018). No setor florestal, Martins et al. (2018) com a disparidade do extrativismo vegetal no Nordeste brasileiro.

Com base na importância dos produtos madeireiros do extrativismo vegetal na economia paraibana e na necessidade de compreensão da distribuição regional, este trabalho analisou o padrão de especialização e localização do valor bruto de produção (VBP) dos produtos madeireiros nativos nas microrregiões da Paraíba, de 1994 a 2017. 


\section{Material e métodos}

\section{Dados utilizados}

Para mensurar a disparidade do valor bruto de produção (VBP) dos produtos madeireiros do extrativismo vegetal utilizou-se o somatório da lenha (Le), do carvão vegetal (CV) e madeira em tora (MT) das microrregiões do estado da Paraíba (Figura 1), no período de 1994 a 2017. Também, foram usados valores do Produto Interno Bruto (PIB) das microrregiões da Paraíba, no período de 1999 a 2016. Essas informações estão disponíveis na Produção da Extração Vegetal e da Silvicultura (PEVS) e no PIB dos municípios, ambos do IBGE. Esses dados foram deflacionados pelo Índice Geral de Preços - Disponibilidade Interna (IGP-DI), ano base $2017=100$ (IPEA, 2018).

Para avaliação da conjuntura do VBP dos produtos madeireiros nas microrregiões foi apresentado o total gerado em 1994, 2000, 2006, 2012 e 2017. Utilizou-se a Taxa de crescimento geométrica (TGC) para observar as alterações (ganhos e perdas) no VBP entre 1994 e 2017. De acordo com Cuenca e Dompieri (2017):

$$
\operatorname{TGC}[\%]=\left[\Delta t \sqrt{\frac{V_{F}}{V_{O}}}-1\right] * 100,0
$$

Em que, $\mathrm{V}_{\mathrm{F}}$ é $\mathrm{VBP}$ dos produtos madeireiros no ano final; $\mathrm{V}_{0}$ refere-se ao VBP do ano inicial; $\Delta \mathrm{t}$ é a variação temporal (expressa em anos).

Figura 1 - Localização geográfica e divisão política das microrregiões na Paraíba

Figure 1 - Geographical location and political division of Paraíba’s microregions

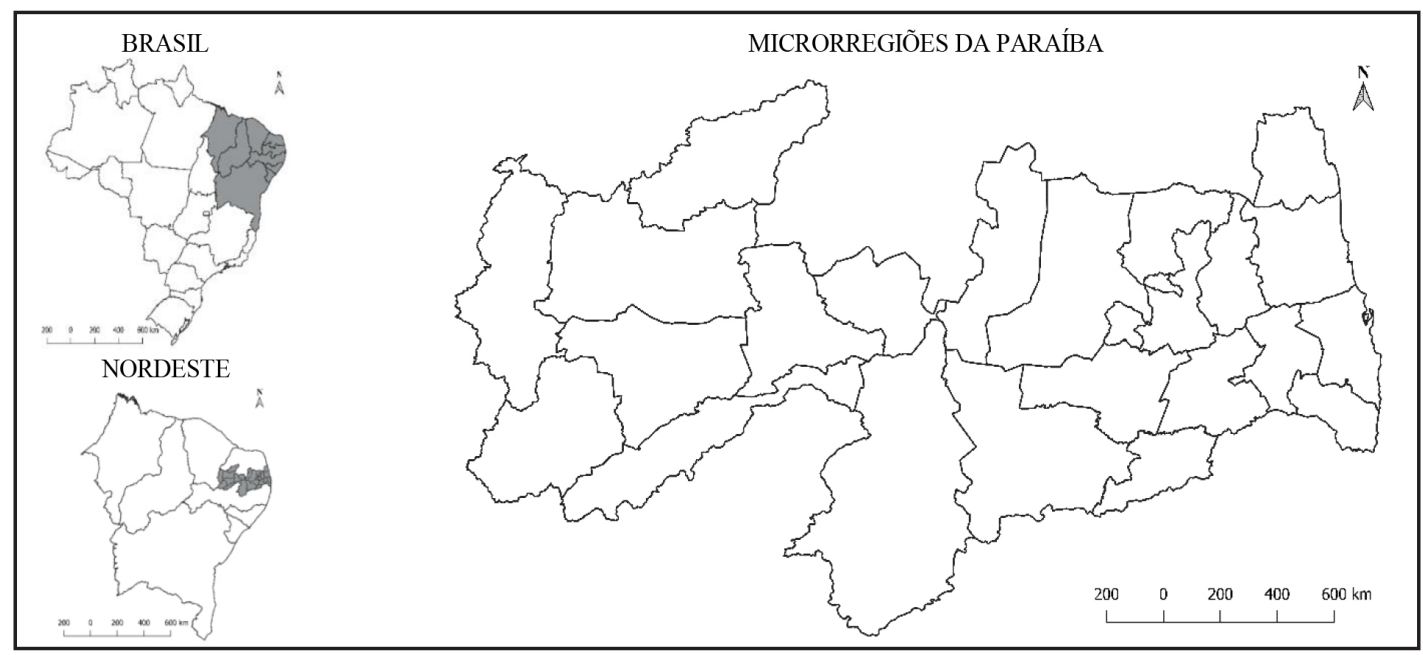

Fonte: IBGE (2017)

\section{Medidas de Localização e de Especialização}

Conforme Haddad (1989), as medidas de localização e especialização são úteis para compreensão dos padrões de especialização e crescimento econômico em uma determinada zona geográfica. As primeiras compreendem a localização de uma determinada atividade entre as microrregiões de estudo, identificando concentração ou dispersão, as medidas locacionais 
foram: o quociente locacional $(\mathrm{Q} L)$, o Coeficiente de localização $(C L)$, o Coeficiente de Associação Geográfica (Cag) e o Coeficiente de Redistribuição (CRED). Por sua vez, as medidas de especialização avaliam estrutura produtiva das regiões de estudo, identificando o grau de especialização em um determinado período. Assim, foram utilizados os Coeficientes de Especialização $(C E)$ e de Reestruturação $(C r)$. A Tabela 1 apresenta os indicadores locacionais e regionais e os intervalos de interpretação de seus resultados.

Tabela 1 - Indicadores locacionais e regionais para os produtos madeireiros

Table 1 - Locational and regional indicators for wood products

\begin{tabular}{|c|c|c|}
\hline Indicador & Equação & Interpretação de Resultados \\
\hline QL & $\frac{E i}{E}$ & $\begin{array}{c}Q L \geq 1 / \text { Concentração significativa } \\
0,50 \leq Q L \leq 0,99 / \text { Concentração média } \\
Q L \leq 0,49 / \text { Concentração fraca }\end{array}$ \\
\hline CL & $C L_{i}=\frac{\sum_{j}\left|\left(\frac{E_{i j}}{E i}-\frac{E_{j}}{E}\right)\right|}{2}$ & $\begin{array}{l}C L=0 / \text { Distribuído igualmente à região } \mathrm{J} \\
C L=1 / \text { Concentração superior à região } \mathrm{J}\end{array}$ \\
\hline Cag & $\operatorname{Cag}_{i k}=\frac{\sum_{j}\left(\left|\frac{E_{i j}}{E_{i}}-\frac{E_{k j}}{E_{k}}\right|\right)}{2}$ & $\begin{array}{c}0,15<\text { Cag }<0=\text { Associação significativa } \\
0,29<\text { Cag } \leq 0,15=\text { Associação média } \\
0,45<\text { Cag } \leq 0,29=\text { Associação fraca } \\
0,45 \leq \text { Cag = Associação nula }\end{array}$ \\
\hline CRED & $C R E D_{i}=\frac{\sum_{j}\left(\left|\frac{E_{i j t_{0}}}{E_{i t_{0}}}-\frac{E_{i j t_{1}}}{E_{i t 1}}\right|\right)}{2}$ & $\begin{array}{c}C R E D=0 / \text { Localização sem mudanças } \\
C R E D=1 / \text { Mudanças na localização }\end{array}$ \\
\hline $\mathrm{CE}$ & $C E_{j}=\frac{\sum_{i}\left|\left(\frac{E_{i j}}{E_{j}}-\frac{E_{i}}{E}\right)\right|}{2}$ & $\begin{array}{c}C E=0 / \text { Padrão de produção constante } \\
C E=1 / \text { Alterou-se o padrão de produção }\end{array}$ \\
\hline $\mathrm{Cr}$ & $C r_{j}=\frac{\sum_{i}\left(\left|\frac{E_{i j t_{1}}}{E_{j t_{1}}}-\frac{E_{i j t_{0}}}{E_{j t_{0}}}\right|\right)}{2}$ & $\begin{array}{c}C r=0 / \text { Não houve reestruturação } \\
C r=1 / \text { Houve reestruturação }\end{array}$ \\
\hline
\end{tabular}

Fonte: Haddad (1989), Lima e Alves (2008), Piacenti, Alves e Lima (2008) e Cruz et al. (2011)

Em que: $Q L=$ Quociente Locacional; $C L=$ Coeficiente de Localização; Cag = Coeficiente de associação geográfica; $C R E D$ = Coeficiente de Redistribuição; $C E$ = Coeficiente de Especialização; $C r$ = Coeficiente de reestruturação; $E_{i j}=$ VBP do produto madeireiro $i$ na microrregião $j ; E_{j}=$ VBP total dos produtos madeireiros na microrregião $j ; E_{i}=\mathrm{VBP}$ do produto madeireiro $i$ na Paraíba; $E=\mathrm{VBP}$ total dos produtos madeireiros na Paraíba; $i$ e $k=$ são tipos de produtos madeireiros; $t_{0}=$ Ano inicial; $t_{1}=$ Ano final.

O quociente locacional $(Q L)$ relaciona a participação relativa do segmento produtivo na economia de uma dada região com a participação relativa desse mesmo segmento em uma região de referência; tendo em vista que o quociente está em função do VBP dos produtos madeireiros, ele aponta a concentração relativa do VBP em determinadas regiões (PIACENTI; ALVES; LIMA 2008).

De acordo com Lima et al. (2006), o coeficiente de localização $(C L)$ relaciona a distribuição percentual do VBP de um determinado produto em uma determinada região com a distribuição percentual do VBP na região de referência. O coeficiente de associação geográfica (Cag) representa 
a associação geográfica entre dois produtos ( $i$ e $k$ ) em uma determinada região comparando as distribuições percentuais do VBP entre microrregiões (LIMA; ALVES, 2008). Piacenti, Alves e Lima (2008) afirmam que o coeficiente de redistribuição $(C R E D)$ trata da relação da distribuição percentual do VBP de um agregado do extrativismo vegetal em uma dada região em relação ao estado da Paraíba, para um período de tempo $\left(t_{0}\right.$ e $\left.t_{1}\right)$, verificando a ocorrência do padrão de concentração ou dispersão espacial no VBP de determinado produto madeireiro do extrativismo vegetal ao longo do tempo. Foram observados os períodos de 2000, 2006, 2012 e 2017 com base em 1994.

O coeficiente de especialização $(C E)$ trata-se de uma medida regional que compara a economia de uma região com a de região referência com base no ano de 2017. O coeficiente de reestruturação $(\mathrm{Cr})$ é uma medida que relaciona a estrutura de produção de uma determinada região entre dois períodos, verificando o grau de mudanças na especialização. Foram observados os períodos de 2000, 2006, 2012 e 2017 com base em 1994, ordenados de forma decrescente com base nos anos de 1994 e 2017.

\section{Resultados e discussão}

A Tabela 2 apresenta a evolução do VBP dos produtos madeireiros para as microrregiões da Paraíba, de 1994 e 2017. O VBP dos produtos madeireiros estadual decresceu a uma taxa de 1,90\% a.a. e pode ser associado ao aumento da participação do setor de serviços no PIB paraíbano. Para Cambota (2015), o segmento de serviços foi a principal atividade econômica no estado, ganhando relevância a partir de 2002 .

Tabela 2 - Evolução do valor bruto de produção (VBP) dos produtos madeireiros para as microrregiões da Paraíba, em milhares de Reais, entre os anos de 1994 e 2017 (IGP-DI, ano base $2017=100$ )

Table 2 - Evolution of the gross production value (VBP) of wood products loggers in the microregions, in thousands of Reais, between 1994 and 2017 (IGP-DI, base year $2017=100$ )

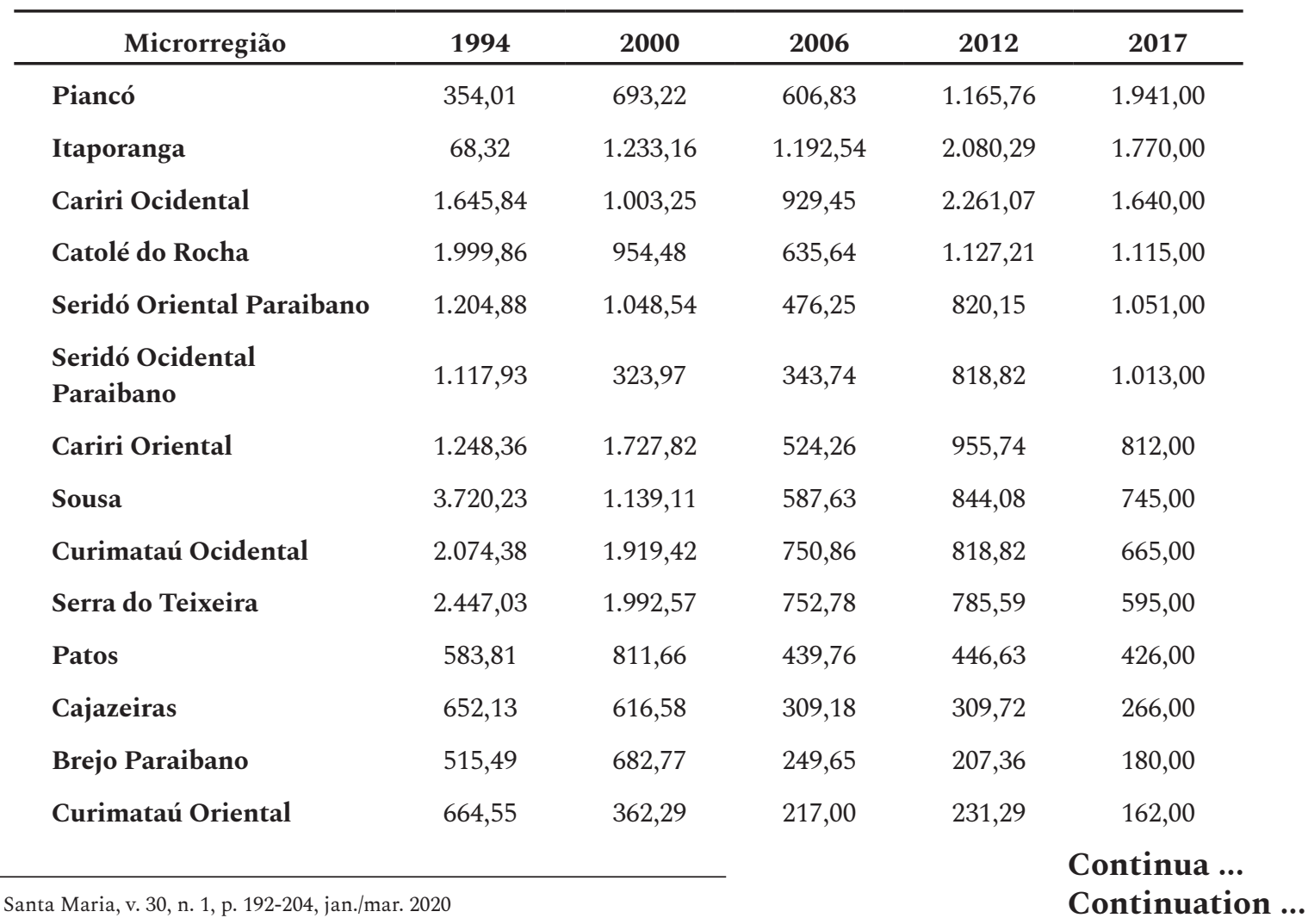


Tabela 2 - Conclusão ...

Table 2 - Conclusion ...

\begin{tabular}{lccccc}
\hline \multicolumn{1}{c}{ Microrregião } & $\mathbf{1 9 9 4}$ & $\mathbf{2 0 0 0}$ & $\mathbf{2 0 0 6}$ & $\mathbf{2 0 1 2}$ & $\mathbf{2 0 1 7}$ \\
\hline Campina Grande & 335,38 & 184,63 & 96,02 & 142,23 & 150,00 \\
Guarabira & 198,74 & 289,13 & 188,20 & 198,06 & 120,00 \\
Umbuzeiro & 378,85 & 149,79 & 65,29 & 93,05 & 101,00 \\
Esperança & 80,74 & 90,57 & 49,93 & 81,08 & 92,00 \\
Itabaiana & 378,85 & 59,22 & 53,77 & 41,21 & 34,00 \\
Litoral Sul & 0,00 & 0,00 & 0,00 & 59,82 & 33,00 \\
Litoral Norte & 223,59 & 17,42 & 142,11 & 13,29 & 9,00 \\
Sapé & 118,00 & 6,97 & 3,84 & 2,66 & 1,00 \\
João Pessoa & 55,90 & 0,00 & 0,00 & 0,00 & 0,00 \\
Paraíba & $20.066,87$ & $15.306,55$ & $8.614,73$ & $13.503,96$ & $12.921,00$ \\
\hline
\end{tabular}

Fonte: IBGE (2019)

O VBP médio estadual dos produtos madeireiros foi de $\mathrm{R} \$ 12,96$ milhões, sendo 1996 o maior (R $\$$ 20,54 milhões) e 2005 o menor (R \$ 8,09 milhões). Em 2005, o PIB foi de R \$32,95 bilhões, a participação do setor de serviços foi de $62,82 \%$, enquanto o agropecuário (incluso extrativismo vegetal) teve quota de apenas 6,35\%. De 2006 a 2016, o PIB paraibano aumentou a uma taxa de $+4,53 \%$ a.a., todavia o setor agropecuário apresentou participação cada vez menor (IBGE, 2019).

O aumento da renda e sua melhor distribuição influenciaram na queda de produção dos produtos madeireiros na Paraíba, tendo em vista que o aumento do PIB per capita colaborou na diminuição do uso residencial da madeira. Segundo Cambota (2015), o incremento de renda populacional foi devido aos programas sociais governamentais, contribuindo com aumento da renda familiar e melhoria da formação e capacitação profissional. A pesar da participação $(18,11 \%)$ do setor industrial no PIB estadual, observou-se melhoria tecnológica e ganhos de eficiência energética no segmento de base florestal, principalmente nos setores de gesso e cerâmica (BRASIL, 2018b).

A lenha foi o produto madeireiro com participação média de $87,25 \%$, seguida do carvão vegetal, com $12,16 \%$ e da madeira em tora, com $0,59 \%$. A elevada produção da lenha justifica-se pela demanda energética do setor residencial rural e do setor industrial, com destaque para cerâmica vermelha e o polo gesseiro de Pernambuco (TRAVASSOS; SOUZA, 2014). A microrregião do Cariri Ocidental, com VBP médio de R\$1,49 milhões (11,52\%), apresentou a maior participação média, nos anos estudados, com $73,28 \%$ do VBP obtido da lenha e $26,72 \%$ do carvão vegetal. Em seguida, estiveram as microrregiões Itaporanga (10,36\%), Serra de Teixeira $(9,27 \%)$ e Souza $(8,07 \%)$ pertencentes às mesorregiões do Sertão paraibano e da Borborema. O semiárido na Paraíba evidencia importância para a exploração madereira, conforme observado por Brasil (2018b) e Coelho Junior et al. (2019a). A partir de 2005, as microrregiões de Serra do Teixeira, de Sousa e de Curimataú Ocidental tiveram queda no VBP dos produtos madeireiros, mas apresentaram aumento do PIB em função do setor de serviços (IBGE, 2019).

As microrregiões situadas na Mata paraibana apresentaram os menores VBP's médio do estado. Segundo Coelho Junior, Burgos e Santos Júnior (2018), a região apresenta baixa participação devido ao grande número de reservas florestais destinadas a preservação. A microrregião de João Pessoa foi a de menor contribuição com média de apenas $\mathrm{R} \$ 9,64$ mil, se considerados todos anos de análise, tendo em vista que apresentou produção apenas entre 1994 e 1999. O Litoral Sul (R $\$ 18,32$ mil), Sapé (R $\$ 36,37$ mil), Esperança (R \$ 68,27 mil) e Litoral Norte ( $\mathrm{R} \$ 79,15 \mathrm{mil})$ completaram as regiões com menor participação.

A Figura 2 apresenta o quociente locacional do VBP dos produtos madeireiros das microrregiões da Paraíba, para o período de 1994 a 2017. Em relação ao VBP da lenha, 13 microrregiões apresentaram classificação constante, durante o período de análise. O Brejo Paraibano, Catolé do Rocha, Esperança Guarabira, Itabaiana, Piancó, Sapé, Seridó Oriental, Seridó Ocidental e Souza foram classificados com 
concentração forte, ou seja, o VBP gerado da produção de lenha apresentou participação muito mais significativa do que os demais produtos madeireiros.

Essas regiões foram observadas no estudo de Coelho Junior, Burgos e Santos Júnior (2018), que identificaram algumas dessas como principais produtoras de lenha do estado. Campina Grande, Serra do Teixeira e Umbuzeiro apresentaram concentração média. As demais microrregiões apresentaram comportamento migratório, com destaque para o Cariri Oriental, que apresentou a maior oscilação entre concentração forte (1998 - 2007, 2010 e 2016) e média (1994 - 1997, 2008 - 2009, 2011 - 2015 e 2017$).$ A microrregião de Esperança apresentou a maior média para o $Q L(1,127)$, com valor acumulado de 1,53 R\$ milhões. De acordo com Reinaldo Filho e Bezerra (2010), a região é apontada com um dos principais polos extratores de lenha do estado.

Para o carvão vegetal, as microrregiões de Patos, Cariri Ocidental, Campina Grande e Umbuzeiro apresentaram concentração forte, durante os anos apresentados na Figura 2, enquanto as microrregiões de Guarabira, Catolé do Rocha, Esperança, Litoral Sul e Sousa apresentaram concentração fraca. As demais regiões apresentaram comportamento migratório entre os níveis de concentração. O Litoral Norte apresentou a maior concentração, com valor médio de $Q L$ de 4,49 , para o período em que houve disponibilidade de dados (1994 -2006), o comportamento deveu-se à baixa produção de lenha. O QL do VBP da madeira em tora só apresentou valores relevantes para a Serra de Teixeira e Cariri Oriental, em 1994, e para Serra de Teixeira, em 1999, com concentração forte, o que se justifica pela baixa extração no restante do estado.

Figura 2 - Evolução do Quociente Locacional $(Q L)$ do valor bruto de produção (VBP) dos produtos madeireiros das microrregiões da Paraíba, de 1994 a 2017

Figure 2 - Evolution of the Locational Quotient $(Q L)$ of the wood product gross production value (GVP) for of Paraíba's microregions, from 1994 to 2017

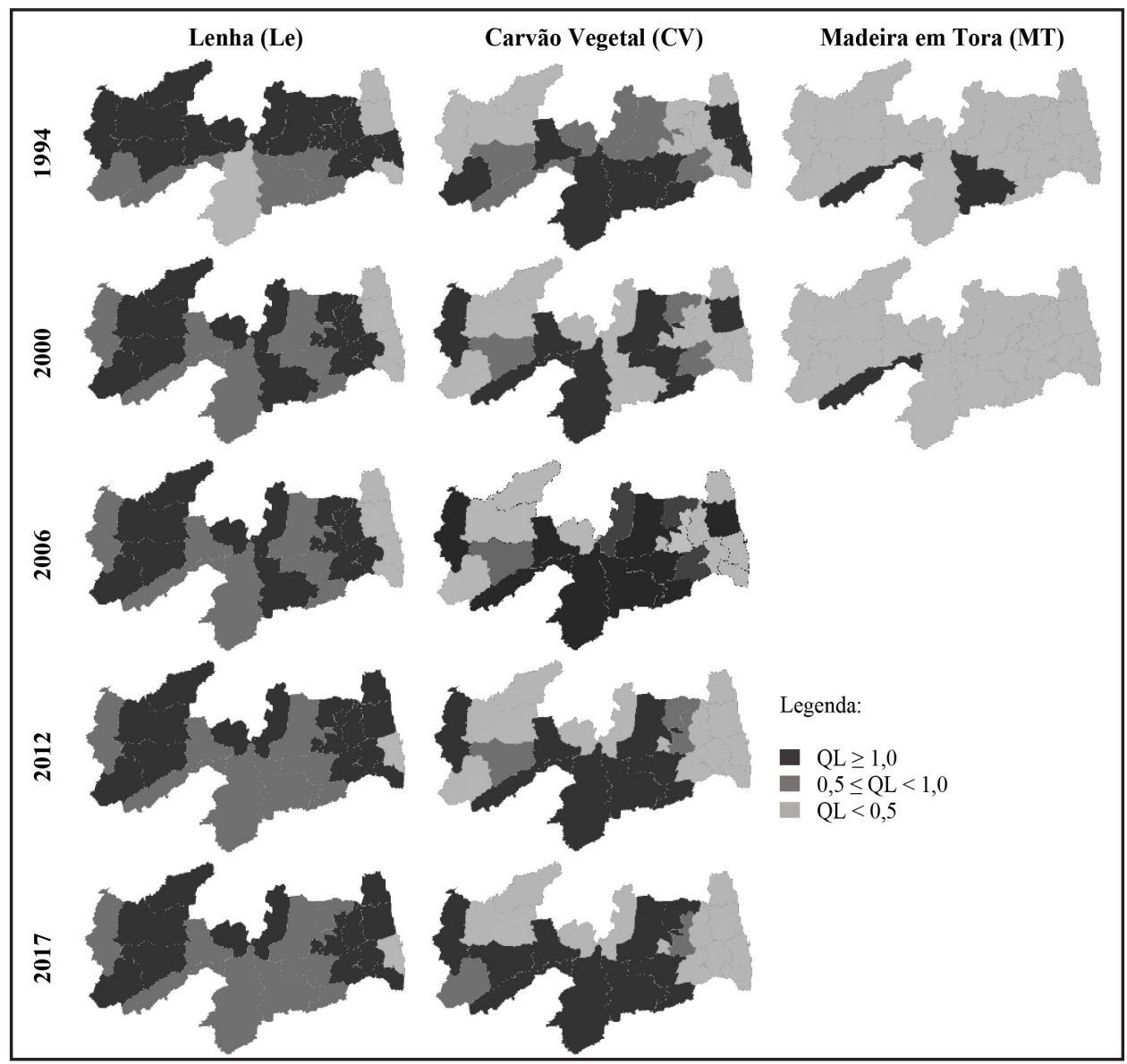

Fonte: Autores (2019) 
A Figura 3 apresenta a Evolução do Coeficiente de Localização $(C L)$ (a) e do Coeficiente de Associação Geográfica (Cag) (b) para o Valor Bruto de Produção dos produtos madeireiros das microrregiões paraibanas, no período de 1994 a 2017. As microrregiões da Paraíba apresentaram o menor $C L$ médio $(0,049)$ para a produção da lenha, mostrando que há uma pequena diferença entre o padrão de extração das microrregiões e o Estado.

O maior valor registrado foi de 0,090, em 1995, que mostrou que o VBP da lenha distribui-se de forma semelhante aos produtos madeireiros total, entre as regiões de estudo, como resultado de sua grande participação na extração madeireira do Estado. Para o carvão vegetal, o valor médio do $C L$ foi de 0,344 , apontando que sua produção esteve localizada em um número menor de microrregiões. Embora o Estado paraibano tenha na lenha o principal produto madeireiro, algumas microrregiões, como Patos, Umbuzeiro e Serra do Teixeira, apresentaram contribuição importante na extração do carvão vegetal, que resultou em uma estrutura produtiva diferenciada, com participação mais expressiva do carvão vegetal para o VBP total. Essas regiões foram identificadas no trabalho de Coelho Junior et al. (2019b) ao analisarem as microrregiões com maior produção de carvão vegetal na Paraíba.

A extração de madeira em tora apresentou a maior diferença na distribuição comparado ao estado, tendo em vista que apenas as microrregiões de Serra de Teixeira e do Cariri Oriental apresentaram produção; o valor médio para o $C L$ da madeira em tora $(0,863)$ confirmou o observado pelos demais índices, demonstrando que o VBP da madeira em tora encontra-se mais concentrado regionalmente que o VBP dos produtos madeireiros total. O Cag da lenha e carvão vegetal apontou associação geográfica fraca entre os produtos, devido o carvão ser um subproduto da extração de lenha e evidenciou o efeito de substituição apresentado pelo $Q L, o$ valor médio do Cag foi de 0,345 para o período estudado.

Figura 3 - Evolução do Coeficiente de Localização $(C L)(a)$ e do Coeficiente de Associação Geográfica $(\mathrm{Cag})(\mathrm{b})$ para o valor bruto de produção (VBP) dos produtos madeireiros das microrregiões paraibanas, de 1994 a 2017

Figure 3 - Evolution of the Location Coefficient $(C L)$ (a) and Geographic Association Coefficient ( $\mathrm{Cag}$ ) (b) of wood products' gross production value (GVP) for the Paraíba's microregions, from 1994 to 2017

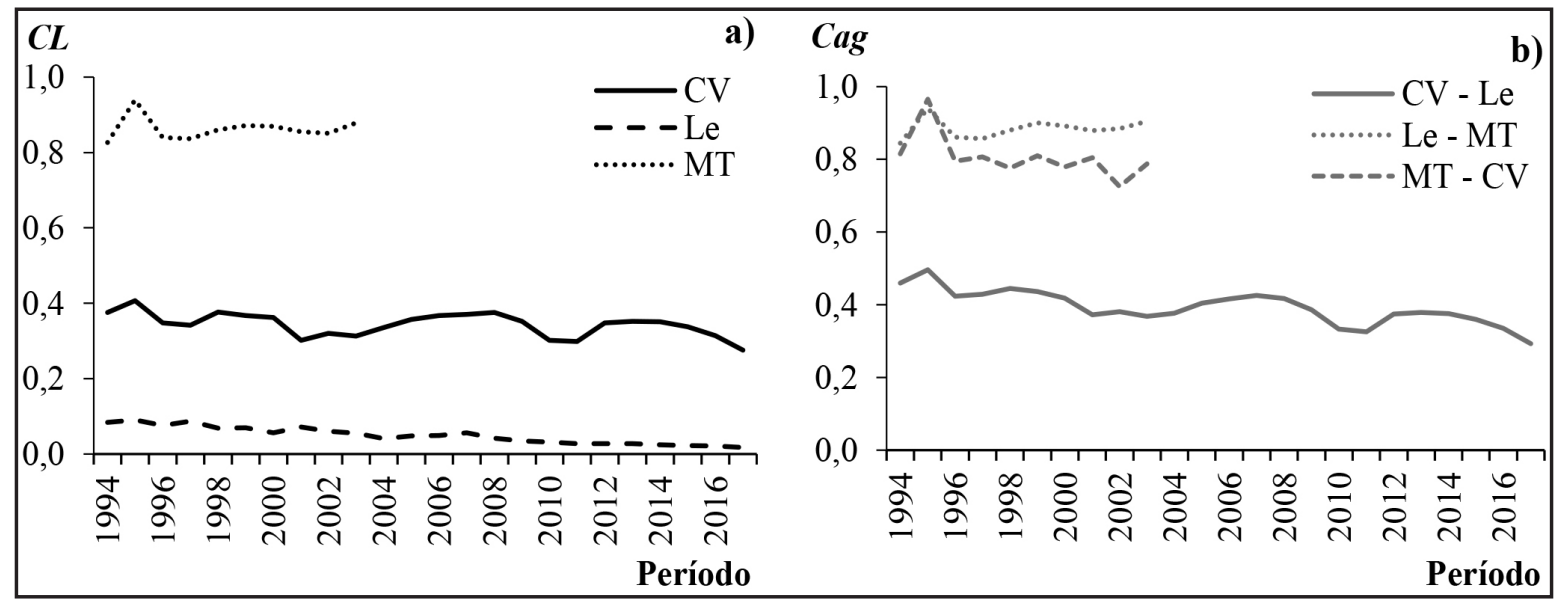

Fonte: Autores (2019) 
Para a associação da lenha com a madeira em tora só houve contabilização entre os anos de 1994 a 2003, devido a inexistência de dados a partir de 2004, o mesmo ocorreu para associação do carvão vegetal com a madeira em tora. O Cag inferiu que não há relação direta entre a produção de lenha e de madeira em tora no estado paraibano, tendo em vista que a extração de madeira em tora se restringiu apenas a duas microrregiões (Cariri Oriental e Serra do Teixeira). Para o carvão vegetal também não foi encontrada associação significativa com base na mesma proposição.

A Tabela 3 apresenta o Coeficiente de redistribuição (CRED) do VBP dos produtos madeireiros para as microrregiões da Paraíba, para 2000, 2006, 2012 e 2017, com base 1994. Para o CRED a lenha apresentou a mudança mais significativa, nos intervalos estudados, seguida do carvão vegetal. O CRED da madeira em tora apontou pouca mudança para o intervalo em que houve disponibilidade de dados. Embora os valores de CRED tenham sido elevados para lenha, não houve alterações significativas entre os produtores do insumo, mantendo-se as regiões do Cariri Ocidental, Cariri Oriental e Curimataú Ocidental como mais participativas, todavia evidenciouse uma queda em seu VBP ao longo dos anos. Os valores elevados de CRED para o carvão vegetal nos anos iniciais de análise resultaram da diminuição do VBP dos principais produtores do insumo, consequentemente as demais microrregiões aumentaram sua participação, tornando o cenário redistribuído; esse efeito pode ser observado nos dados da produção do extrativismo vegetal do IBGE (2018).

Tabela 3 - Coeficiente de redistribuição $(C R E D)$ do valor bruto de produção (VBP) dos produtos madeireiros para as microrregiões da Paraíba, para 2000, 2006, 2012 e 2014 com base 1994

Table 3 - Redistribution coefficient (CRED) of wood product gross production value (GVP) for Paraíba's microregions for 2000, 2006, 2012 and 2014 with base 1994

\begin{tabular}{lcccc}
\hline \multicolumn{1}{c}{ Região } & $\mathbf{1 9 9 4 - \mathbf { 2 0 0 0 }}$ & $\mathbf{1 9 9 4} \mathbf{- 2 0 0 6}$ & $\mathbf{1 9 9 4} \mathbf{- 2 0 1 2}$ & $\mathbf{1 9 9 4} \mathbf{- 2 0 1 7}$ \\
\hline Lenha & 0,2841 & 0,3176 & 0,3891 & 0,4219 \\
Carvão Vegetal & 0,3685 & 0,3682 & 0,2522 & 0,3761 \\
Madeira em Tora & 0,1354 & - & - & - \\
\hline
\end{tabular}

Fonte: Autores (2019)

A Tabela 4 apresenta o ranking do coeficiente de especialização $(C E)$ do VBP dos produtos madeireiros às microrregiões da Paraíba, de 1994 a 2014. Observou-se que a composição do extrativismo vegetal dos produtos madeireiros das microrregiões foi semelhante à estrutura extrativista do estado da Paraíba, para a maioria dos anos analisados. A microrregião de maior valor médio de $C E$ foi o Litoral Norte $(0,3539)$, que embora tenha apresentado pequena produção madeireira, destacou-se pela extração de lenha nos anos iniciais de análise. Por sua vez, as regiões de João Pessoa e Piancó apresentaram diversos valores nulos, o que proporcionou os menores $C E$ médios, com 0,015 e 0,045 , respectivamente. 
Tabela 4 - Ranking do coeficiente de especialização $(C E)$ do VBP dos produtos madeireiros para as microrregiões da Paraíba, de 1994 a 2014

Table 4 - Ranking of the GVP specialization coefficient $(C E)$ of the timber products for Paraíba's microregions, from 1994 to 2014

\begin{tabular}{|c|c|c|c|c|c|c|c|}
\hline & Microrregião & 1994 & 2000 & 2006 & 2012 & 2017 & Média \\
\hline $1^{\circ}$ & Patos & 0,0149 & 0,1157 & 0,1561 & 0,1203 & 0,1333 & 0,1362 \\
\hline $2^{\circ}$ & Umbuzeiro & 0,2277 & 0,1355 & 0,1163 & 0,0697 & 0,0992 & 0,1121 \\
\hline $3^{\circ}$ & Serra do Teixeira & 0,0917 & 0,1479 & 0,0672 & 0,0538 & 0,0652 & 0,1058 \\
\hline $4^{\circ}$ & Litoral Norte & 0,5401 & 0,4797 & 0,8405 & 0,0731 & 0,0592 & 0,3539 \\
\hline $5^{\circ}$ & Sapé & 0,1444 & 0,1301 & 0,1190 & 0,0731 & 0,0592 & 0,1071 \\
\hline $6^{\circ}$ & Litoral Sul & 0,0000 & 0,0000 & 0,0000 & 0,0731 & 0,0592 & 0,0493 \\
\hline $7^{\circ}$ & Campina Grande & 0,0401 & 0,0117 & 0,0810 & 0,0297 & 0,0541 & 0,0571 \\
\hline $8^{\circ}$ & Guarabira & 0,1345 & 0,1181 & 0,1088 & 0,0664 & 0,0509 & 0,1017 \\
\hline $9^{\circ}$ & Cajazeiras & 0,1208 & 0,0209 & 0,0674 & 0,0470 & 0,0498 & 0,0650 \\
\hline $10^{\circ}$ & Catolé do Rocha & 0,1535 & 0,1119 & 0,1099 & 0,0625 & 0,0484 & 0,1045 \\
\hline $11^{\circ}$ & Esperança & 0,1201 & 0,1301 & 0,1190 & 0,0568 & 0,0483 & 0,1099 \\
\hline $12^{\circ}$ & $\begin{array}{c}\text { Seridó Ocidental } \\
\text { Paraibano }\end{array}$ & 0,1026 & 0,0871 & 0,0687 & 0,0504 & 0,0375 & 0,0699 \\
\hline $13^{\circ}$ & Sousa & 0,1136 & 0,0934 & 0,0798 & 0,0495 & 0,0350 & 0,0782 \\
\hline $14^{\circ}$ & Cariri Ocidental & 0,5311 & 0,3172 & 0,0980 & 0,0797 & 0,0310 & 0,1458 \\
\hline $15^{\circ}$ & Itabaiana & 0,0495 & 0,0713 & 0,0476 & 0,0409 & 0,0298 & 0,0553 \\
\hline $16^{\circ}$ & Curimataú Ocidental & 0,0174 & 0,0230 & 0,0140 & 0,0275 & 0,0295 & 0,0609 \\
\hline $17^{\circ}$ & Seridó Oriental Paraibano & 0,0785 & 0,0869 & 0,0585 & 0,0310 & 0,0288 & 0,0696 \\
\hline $18^{\circ}$ & Itaporanga & 0,1815 & 0,0934 & 0,0819 & 0,0444 & 0,0253 & 0,0867 \\
\hline $19^{\circ}$ & Brejo Paraibano & 0,1609 & 0,1097 & 0,0805 & 0,0283 & 0,0203 & 0,0809 \\
\hline $20^{\circ}$ & Curimataú Oriental & 0,1690 & 0,0532 & 0,0570 & 0,0157 & 0,0087 & 0,0469 \\
\hline $21^{\circ}$ & Piancó & 0,0742 & 0,0346 & 0,0557 & 0,0321 & 0,0047 & 0,041 \\
\hline $22^{\circ}$ & Cariri Oriental & 0,2308 & 0,0797 & 0,0274 & 0,0200 & 0,0036 & 0,0683 \\
\hline $23^{\circ}$ & João Pessoa & 0,0401 & 0,0000 & 0,0000 & 0,0000 & 0,0000 & 0,0156 \\
\hline
\end{tabular}

Fonte: Autores (2019)

A maior especialização $(0,8417)$ foi em 2005 para microrregião Litoral Norte, que apresentou $100 \%$ da extração madeireira para lenha, enquanto a menor foi encontrada para João Pessoa com diversos resultados nulos se dá pela falta de produção.

A Tabela 5 apresenta o ranking do coeficiente de reestruturação $(\mathrm{Cr})$ do Valor Bruto de Produção de produtos madeireiros do extrativismo vegetal das microrregiões da Paraíba, entre 2000, 2006, 2012 e 2017, com base em 1994. João Pessoa e o Cariri Ocidental apresentaram as maiores médias de $\mathrm{Cr}$ entre todas as microrregiões da Paraíba, com 0,500 e 0,488, respectivamente. Para João Pessoa observou-se elevada reestruturação em razão da falta de dados de extração a partir de 2000. 
Para o Cariri Ocidental a estrutura era composta por $71,32 \%$ da extração para carvão vegetal, em 1994, passando a ser apenas 43,75\%, em 2000, 21,69\% (2006), 15,28\% (2012) e 9,02\% (2017). Outras regiões que apresentaram reestruturação significativa em todos os períodos foram a de Itaporanga com valor médio de $\mathrm{Cr}$ de 0,327 e o Cariri Oriental com 0,332. A microrregião de menor $\mathrm{Cr}$ médio foi Patos que apresentou em todos os anos produção de lenha sempre superior a $68,70 \%$ dos produtos madeireiros total. O Brejo Paraibano e a microrregião de Catolé do Rocha também apresentaram reestruturação nulas ou próximo a zero.

Os resultados observados pelos índices de especialização e localização apresentaram complementariedade e indicaram a grande importância da lenha no agregado dos produtos madeireiros do extrativismo vegetal no estado da Paraíba, além de ressaltarem as microrregiões situadas no semiárido como principais participantes da oferta dessa biomassa florestal.

\section{Conclusão}

A partir das análises realizadas notou-se que a lenha foi o principal produto madeireiro extraído nas microrregiões da Paraíba, dada a elevada demanda energética residencial e industrial desse insumo, com destaque para as indústrias cerâmicas localizadas no estado e o polos gesseiros instalados em estados vizinhos. Apenas a microrregião do Serra do Teixeira apresentou relevância para a extração da madeira em tora no estado, atribuindo elevados valores de $Q L$ e $C L$ para o produto, nos anos iniciais da análise.

Tabela 5 - Ranking do coeficiente de reestruturação $(\mathrm{Cr})$ do valor bruto de produção (VBP) de produtos madeireiros do extrativismo vegetal das microrregiões da Paraíba, para 2000, 2006, 2012 e 2017 com base em 1994

Table 5 - Ranking of the restructuring coefficient $(\mathrm{Cr})$ of wood products' gross production value (GVP) for the Paraíba's microregions for 2000, 2006, 2012 and 2017 based on 1994

\begin{tabular}{lcccccc}
\hline & Microrregião & $\mathbf{1 9 9 4 - 2 0 0 0}$ & $\mathbf{1 9 9 4 - 2 0 0 6}$ & $\mathbf{1 9 9 4 - 2 0 1 2}$ & $\mathbf{1 9 9 4 - 2 0 1 7}$ & Média \\
\hline $\mathbf{1}^{\circ}$ & João Pessoa & 0,5000 & 0,5000 & 0,5000 & 0,5000 & 0,5000 \\
$\mathbf{2}^{\circ}$ & Cariri Ocidental & 0,2757 & 0,4963 & 0,5604 & 0,6230 & 0,4888 \\
$\mathbf{3}^{\circ}$ & Litoral Norte & 0,1222 & 0,2372 & 0,7222 & 0,7222 & 0,451 \\
$\mathbf{4}^{\circ}$ & Cariri Oriental & 0,3775 & 0,3363 & 0,3347 & 0,3651 & 0,3534 \\
$\mathbf{5}^{\circ}$ & Itaporanga & 0,3269 & 0,3266 & 0,3349 & 0,3297 & 0,3295 \\
$\mathbf{6}^{\circ}$ & Litoral Sul & 0,0000 & 0,0000 & 0,5000 & 0,5000 & 0,2500 \\
$\mathbf{7}^{\circ}$ & Umbuzeiro & 0,154 & 0,1745 & 0,2670 & 0,2514 & 0,2117 \\
$\mathbf{8}^{\circ}$ & Serra do Teixeira & 0,1089 & 0,1066 & 0,1066 & 0,1066 & 0,1072 \\
$\mathbf{9}^{\circ}$ & Itabaiana & 0,0887 & 0,0761 & 0,1153 & 0,1181 & 0,0996 \\
$\mathbf{1 0}^{\circ}$ & Campina Grande & 0,0901 & 0,0222 & 0,1194 & 0,1089 & 0,0852 \\
$\mathbf{1 1}^{\circ}$ & Seridó Oriental & 0,0754 & 0,0581 & 0,0764 & 0,0881 & 0,0745 \\
$\mathbf{1 2}^{\circ}$ & Esperança & 0,0769 & 0,0769 & 0,0605 & 0,0661 & 0,0701 \\
$\mathbf{1 3}^{\circ}$ & Curimataú Ocidental & 0,0363 & 0,0466 & 0,0790 & 0,0909 & 0,0632 \\
$\mathbf{1 4}^{\circ}$ & Cajazeiras & 0,0651 & 0,1101 & 0,0440 & 0,0328 & 0,0630
\end{tabular}


Tabela 5 - Conclusão ...

Table 5 - Conclusion ...

\begin{tabular}{lcccccc}
\hline & Microrregião & $\mathbf{1 9 9 4 - 2 0 0 0}$ & $\mathbf{1 9 9 4 - 2 0 0 6}$ & $\mathbf{1 9 9 4 - 2 0 1 2}$ & $\mathbf{1 9 9 4 - 2 0 1 7}$ & Média \\
\hline $\mathbf{1 5}^{\circ}$ & Seridó Ocidental & 0,0514 & 0,0442 & 0,0717 & 0,0727 & 0,0600 \\
$\mathbf{1 6}^{\circ}$ & Piancó & 0,0273 & 0,0595 & 0,0818 & 0,0589 & 0,0569 \\
$\mathbf{1 7}^{\circ}$ & Guarabira & 0,0505 & 0,0523 & 0,0558 & 0,0542 & 0,0532 \\
$\mathbf{1 8}^{\circ}$ & Sapé & 0,0526 & 0,0526 & 0,0526 & 0,0526 & 0,0526 \\
$\mathbf{1 9}^{\circ}$ & Sousa & 0,0468 & 0,0443 & 0,0599 & 0,0593 & 0,0525 \\
$\mathbf{2 0}^{\circ}$ & Curimataú Oriental & 0,0489 & 0,0339 & 0,0294 & 0,0399 & 0,0380 \\
$\mathbf{2 1}^{\circ}$ & Patos & 0,0446 & 0,0836 & 0,0020 & 0,0010 & 0,0328 \\
$\mathbf{2 2}^{\circ}$ & Catolé do Rocha & 0,0252 & 0,0344 & 0,0329 & 0,0327 & 0,0313 \\
$\mathbf{2 3}^{\circ}$ & Brejo Paraibano & 0,0157 & 0,0023 & 0,0087 & 0,0027 & 0,0074 \\
\hline
\end{tabular}

Fonte: Autores (2019)

O maior valor de CRED foi registrado para a lenha no intervalo de 1994 e 2017, refletindo a reestruturação crescente, identificada em todos os períodos estudados. As microrregiões do Litoral Norte e do Cariri Ocidental apresentaram elevada especialização destacando-se a produção de lenha, em detrimento aos demais produtos. Por fim, as regiões do Litoral Norte, Cariri Ocidental, João Pessoa e Litoral Sul foram as que apresentaram maior mudança no padrão de extração dos produtos madeireiros com relação a 1994, associado a diminuição da produção do carvão vegetal no litoral paraibano.

As medidas de localização e especialização apontaram que as microrregiões do interior (Sertão paraibano e Borborema) do estado são as que apresentam maior contribuição para o VBP dos produtos madeireiros, influenciado pela demanda de biomassa lenhosa residencial e industrial. A partir deste estudo é possível a orientação de políticas públicas que promovam o extrativismo vegetal de forma renovável e útil para o desenvolvimento de regiões.

\section{Referências}

BRASIL. Ministério do Meio Ambiente. Produtos madeireiros e não madeiros. Brasília, [2018a]. Disponível em: http://www.mma.gov.br/florestas/manejo-florestal-sustent\%C3\%A1vel/produtosmadeireiros-e-n\%C3\%A3o-madeireiros.html. Acesso em: 11 mar. 2019.

BRASIL. Ministério do Meio Ambiente. Biomassa para energia no Nordeste: atualidade e perspectivas. Brasília: Ministério do Meio Ambiente; Programa das Nações Unidas para o Desenvolvimento [2018b]. Disponível em: http://www.mma.gov.br/phocadownload/gestão_ territorial/desertificação/livro_APNE_NE_AGO20.pdf. Acesso em: 28 jul. 2019.

CAMBOTA, J. N. Desempenho da economia estadual. In: BEZERRA, F. J. A. et al. (org.). Perfil socioeconômico da Paraíba. Fortaleza: Banco do Nordeste do Brasil, 2015.

CARVALHO, A. V. et al. Arranjos produtivos locais de agricultura temporária no estado do Pará: uma aplicação do modelo de análise de componentes principais. Agroecossistemas, Belém, v. 9 , n. 2, p. 19-42, abr./jun. 2018.

COELHO JUNIOR, L. M.; BURGOS, M. C.; SANTOS JÚNIOR, E. P. Concentração regional da produção de lenha da Paraíba. Ciência Florestal, Santa Maria, v. 28, n. 4, p. 1729-1740, out./dez. 2018.

COELHO JUNIOR, L. M. et al. Regional concentration of the gross value of production of 
firewood in Paraíba. Floram, Seropédica, v. 26, n. 3, p. e20170887, 2019a.

COELHO JUNIOR, L. M. et al. Regional concentration of charcoal production in Paraíba state, Brazil (1994-2016). Revista Árvore, Viçosa, MG, v. 43, n. 1, p. e430105, 2019b.

CUENCA, M. A. G.; DOMPIERI, M. H. G. Dinâmica espacial da canavicultura e análise dos efeitos sobre o valor bruto da produção, na região dos tabuleiros costeiros da Paraíba, Pernambuco e Alagoas. Revista Econômica do Nordeste, Fortaleza, v. 47, n. 4, p. 91-106, out./dez. 2017.

CROMLEY, R. G.; HANINK, D. M. Focal location quotients: specification and applications. Geographical Analysis, Columbus, v. 44, n. 4, p. 398-410, out./dez. 2012.

CRUZ, B. D. O. et al. Economia regional e urbana: teorias e métodos com ênfase no Brasil. [S. l.: s. n.], 2011.

GOSCHIN, Z. et al. Regional specialization and geographic concentration of industries in Romania. South-Eastern Europe Journal of Economics, Thessaloniki, v. 7, n. 1, p. 99-113, jan./ jun. 2015.

HADDAD, P. R. Medidas de localização e de especialização. In: HADDAD, P. R. et al. (org.). Economia regional: teorias e métodos de análise. Fortaleza: BNB; ETENE, 1989.

IBGE. Malhas digitais. Rio de Janeiro: IBGE, [S. l. 2017]. Disponível em: http://mapas.ibge.gov. $\mathrm{br} / \mathrm{pt} / \mathrm{bases}-\mathrm{e}-\mathrm{referenciais/bases-cartograficas/malhas-digitais.} \mathrm{Acesso} \mathrm{em:} 15$ out. 2018.

IBGE. Produção da Extração Vegetal e da Silvicultura - PEVS. [S. l., 2018]. Disponível em: www2.sidra.ibge.gov.br/bda/tabela/listabl.asp? $c=292 \& z=t \& o=18$. Acesso em: 20 out. 2018.

IBGE. Produto Interno Bruto dos municípios. [S. 1., 2019]. Disponível em: https://www.ibge.gov. br/explica/pib.php. Acesso em: 03 nov. 2019.

IPEA. IPEADATA: Índice Geral de Preços: disponibilidade Interna. [S. l., 2018]. Disponível em: www.ipeadata.gov.br/Default.aspx. Acesso em: 20 out. 2018.

LIMA, J. F.; ALVES, L. R. Localização, concentração e vantagem competitiva dos ramos produtivos na geoeconomia paranaense. Caderno de Geografia, Belo Horizonte, v. 18, n. 29, p. 98-124, jul./dez. 2008.

LIMA, J. F. et al. Análise Regional das Mesorregiões do estado do Paraná no final do século XX. Revista Análise Econômica, Porto Alegre, v. 24, n. 46, p. 7-26. set. 2006.

LUCENA, R. F. P. et al. Uso de recursos vegetais da Caatinga em uma comunidade rural no Curimataú Paraibano (Nordeste do Brasil). Polibotánica, México, n. 34, p. 237-258, ago. 2012.

MARTINS, K. L. C. et al. Plant extractivism production disparity between Northeast Brazil and Brazil. Floresta e Ambiente, Seropédica, v. 25, n. 4, p. e20160456, out./dez. 2018.

MATTEI, T. F.; MATTEI, T. S. Métodos de Análise Regional: um estudo de localização e especialização para a Região Sul do Brasil. Revista Paranaense de Desenvolvimento, Curítiba, v. 38, n. 133, p. 227-243, jul./dez. 2018.

MAZUR, A. I.; ROMERO, E. A.; ECKER, A. E. A. Análise Locacional da produção das principais culturas na microrregião de Campo Mourão - Paraná. Revista em Agronegócios e Meio Ambiente, Maringá, v. 6, n. 1, p. 31-45, jan./abr. 2013.

PIACENTI, C.; ALVES, L. R.; LIMA, J. F. O Perfil Locacional do Emprego Setorial no Brasil. Revista Econômica do Nordeste, Fortaleza, v. 39, n. 3, p. 482-502, jul./set. 2008.

REINALDO FILHO, L. L.; BEZERRA, F.D. Informe setorial cerâmica vermelha. Fortaleza: Banco do Nordeste, 2010. 22 p.

SILVA, A. C.; RODRIGUES, E. A. G. A. Viticultura nas Microrregiões do Rio Grande do Sul e sua Distribuição Locacional. Orbis Latina, Foz do Iguaçu, v. 8, n. 1, p. 05-20, jan./jun. 2018.

SOUSA, R. B. et al. Locational Analysis of the Productive Structure of the Micro-Region of Porto Nacional. Baru, Goiânia, v. 3, n. 2, p. 191-209, jul./dez. 2018.

TRAVASSOS, I. S.; SOUZA, B. I. Os negócios da lenha: indústria, desmatamento e desertificação no Cariri paraibano. GEOUSP - Espaço e Tempo, São Paulo, v. 18, n. 2, p. 329-340, jul./dez. 2014. 